\title{
A formação política de uma comunidade de imigrantes alemães no sul do Brasil: o caso de Santa Cruz do Sul (da Primeira República ao Regime Militar, I889-1965)
}

Andrius Estevam Noronha'

\section{Resumo}

Esse trabalho aborda um estudo sobre a formação política de uma comunidade de imigrantes alemães no sul do Brasil, mais especificamente o Município de Santa Cruz do Sul, localizado a 200 km de Porto Alegre, capital do Estado do Rio Grande do Sul. O recorte temporal dessa análise está situado entre os anos de 1889, período de implantação da República, até 1965, ano de implantação do Ato Institucional n 02 no contexto do Regime Militar. A partir de uma revisão bibliográfica sobre a história política local, apoiada em fontes jornalísticas, institucionais e no banco de dados eleitorais de Santa Cruz do Sul pretendemos descrever a dinâmica da política local em quatro partes: a primeira, uma análise da fragilidade da cultura democrática local e sua tendência em aderir ao autoritarismo e ao conservadorismo; a segunda, uma abordagem sobre as relações entre política e religião na Primeira República; a terceira, uma caracterização da cultura do continuísmo e conservadorismo eleitoral que se perpetuou após a Revolução de 1930; a quarta, uma descrição da posição da elite local no movimento pela Legalidade e na implantação do Regime Militar.

Palavras-chave: Santa Cruz do Sul. Autoritarismo. História política local/regional. Regime militar. Brasil República.

I Doutor em História, Professor da Universidade Federal do Amapá (UNIFAP). E-mail:andriusds@hotmail.com

\section{$(\mathrm{cc})) \mathrm{Br}$}

Direito autoral e licença de uso: Este artigo está licenciado sob uma Licença Creative Commons. Com essa licença você pode compartilhar, adaptar, para qualquer fim, desde que atribua a autoria da obra, forneça um link para a licença, e indicar se foram feitas alterações. 


\section{Introdução}

As pesquisas que têm Santa Cruz do Sul como estudo de caso indicam que as elites locais tendiam a ser cooptadas pela política regional e nacional, sendo influenciadas pela dinâmica ocorrida nessas escalas. Construiremos um painel da evolução política da cidade com o objetivo de visualizar os posicionamentos e a capacidade de mobilizaçáo liderada pela elite frente às transformações que ocorreram em âmbito estadual e nacional. A cidade está localizada a $200 \mathrm{~km}$ da capital do Estado do Rio Grande do Sul, Porto Alegre, e teve sua origem na imigração alemã na segunda metade do século XIX. Sua principal atividade econômica é a produção fumageira, amplamente abordada em estudos nas diferentes áreas do conhecimento: Economia, Sociologia, História, Antropologia e Ciência Política.

Além do interesse de vários pesquisadores em entender a dinâmica local, a cidade conta com uma estrutura universitária que contribuiu para ampliar e qualificar os trabalhos acadêmicos sobre sua historiografia local. Resumidamente, podemos apontar alguns estudos, por exemplo, o de Silvana Krause (2002), que analisou o comportamento da elite de Santa Cruz do Sul na implantação da República, nas relaçóes com o Partido Republicano Riograndense (PRR), na Revolução Federalista e na Revolução de 1930; Olgário Vogt (1997) analisou as transformaçóes na economia fumageira local com a instalação da empresa anglo-americana Britsh American Tobacco em 1917 (a partir de 1955 passou a ser Souza Cruz); Marco André Cadoná (2002) analisou a participação dos empresários e políticos locais no movimento pela Legalidade; minha pesquisa de doutorado (NORONHA, 2012) foi sobre um estudo prosopográfico da elite local de Santa Cruz do Sul com o intuito de compreender a rede de relaçóes da comunidade por meio da perspectiva religiosa. $\mathrm{O}$ corpus documental dessa pesquisa foi constituído por necrológios, jornais e entidades patronais que apresentam na sua narrativa informaçóes de cunho político.

A quantidade de pesquisas sobre a história de Santa Cruz do Sul não caberia nesse artigo; portanto, nos limitaremos a compreender o comportamento político dessa comunidade entre 1889 até 1965. Para isso, dividimos essa análise em quatro partes: a primeira aborda a cultura política local, que se caracteriza pela fragilidade de uma prática democrática e pela 
tendência em aderir ao autoritarismo, à violência e ao conservadorismo; a segunda aborda o esvaziamento da cisão religiosa na política local no contexto da I República através de um panorama do desempenho eleitoral entre católicos, representados pelo Partido do Centro Católico (PCC), e protestantes, representados pelo Partido Liberal (Federalistas), para que possamos compreender a progressiva estratégia do Partido Republicano Riograndense em cooptar lideranças dessas duas forças eleitorais da cidade; a terceira aborda a consolidaçáo de uma coesão local frente a disputas nacionais objetivando estratégias de desenvolvimento econômico para a indústria de Santa Cruz no pós-1930 e a evolução eleitoral no contexto democrático; a quarta faz uma análise da atuação da elite local na Legalidade e implantação do Regime Militar.

\section{A fragilidade de uma cultura democrática: a prática política e eleitoral de Santa Cruz do Sul}

A partir da análise das referências bibliográficas amplamente discutidas nos campos da Sociologia, História, Antropologia - Silvana Krause (2002), Marco André Cadoná (2002), Olgário Vogt (1997), Luciana Job (2003) - e, mais especificamente, no campo da Ciência Política, - João Pedro Schmidt (2004a, 2004b 2004c) -, construímos uma radiografia da cultura política de Santa Cruz do Sul ao longo do século XX. Os pesquisadores permitem observar, de um lado, a tendência da elite em aderir aos partidos hegemônicos em âmbito estadual e nacional e, por outro, a facilidade de setores médios urbanos serem cooptados por ideologias autoritárias no período entre guerras, como o nazismo e o integralismo.

Em relação à análise da dinâmica partidária, Schmidt afirma que há uma tendência de a elite, tanto no executivo quanto no legislativo municipal, se aproximar dos partidos ligados ao campo "liberal-conservador"2. $\mathrm{O}$ grupo de partidos que congregavam esse campo mostrou-se hegemô-

2 João Pedro Schmidt emprega os conceitos liberal-conservador e progressista-populista nos períodos de 1945 até 1985 , sem entrar em detalhes sobre eles. O autor procura identificar a posição desses partidos à luz da conjuntura histórica de cada período no Brasil pós-Estado Novo. Entre 1945 e 1964, os liberais conservadores eram o Partido Social Democrático (PSD), União Democrática Nacional (UDN) e Partido Libertador (PL), já o progressista populista era o Partido Trabalhista Brasileiro (PTB); na ditadura o primeiro grupo vai ser a Aliança Renovadora Nacional (ARENA) e o segundo o Movimento Democrático Brasileiro (MDB). 
nico entre 1945 e 1964 em relação ao conjunto de todos os municípios do Rio Grande do Sul. Na cidade de Santa Cruz do Sul, o Partido Social Democrático (PSD) e a União Democrática Nacional (UDN) obtinham expressiva votação e estiveram no comando do executivo em quase todas as gestôes do período. Schmidt (2004a) registra que, do ponto de vista ideológico, a comunidade tendia a apoiar representantes da elite política conservadora, tanto nas eleiçóes nacionais quanto regionais.

Esse comportamento conservador pode ser explicado, principalmente, por dois motivos: em primeiro lugar, pela trajetória histórica de tolerância ou mesmo aceitação de grupos políticos de extrema direita que se organizaram no município; em segundo lugar, pela própria conjuntura nacional/ estadual, marcada de um lado, pela imposiçáo do movimento de nacionalização cultural por parte de Vargas, por outro pelo autoritarismo e intervencionismo de Estado, desde a Primeira República, por meio da cooptaçáo de integrantes da elite local pelo Partido Republicano Rio-Grandense. Esse último fato complicou a capacidade de negociação da elite local, pois a cidade era oriunda da colonização alemã e tinha no seu discurso regional a questáo étnica como determinante para o sucesso empresarial.

No entanto, a Campanha de Nacionalização posta em prática pelo primeiro governo Vargas (1930-1945), contribuiu para que várias comunidades de descendentes de imigrantes alemães e italianos deslocassem seu discurso regional/local, anteriormente fundamentado no fator étnico, para o econômico. As cidades passaram a exaltar seu principal produto de exportação. Como exemplo, temos a cidade de Novo Hamburgo, fundada por imigrantes alemães, que organizaram a Festa Nacional do Calçado; a cidade de Caxias do Sul, fundada por imigrantes italianos, que organizaram a Festa Nacional da Uva e do Vinho. Na mesma esteira de mudanças, a partir de 1949, a elite de Santa Cruz do Sul iniciou um movimento cultural de organizaçáo e promoçáo da Festa Nacional do Fumo.

Pesquisas realizadas por Olgário Vogt (2007) demonstram que, na década de 1930, foram organizadas células do Partido Nazista e da Ação Integralista Brasileira (AIB) que atuaram na cidade. Para o autor, não seria estranho, nesse período, algumas pessoas da comunidade, simpatizantes do nazismo, se cumprimentarem como na Alemanha da década de 1930 
com o jargão: "Heil Hitler". Para Schmidt (2004b) a formação do Partido Nazista na comunidade de Santa Cruz do Sul deve ser avaliada, sobretudo, por sua peculiaridade local; afinal, as notícias vindas da Alemanha e o sentimento de pertencimento ao Estado alemáo constituíram bases para a formação cultural dos pequenos núcleos isolados no Rio Grande do Sul.

$\mathrm{Na}$ cidade, o núcleo se reunia no Hotel Rathskeller. O perfil dos integrantes foi composto por imigrantes alemães que residiam na década de 1930 em Santa Cruz do Sul com a intenção de cooptar alguns comerciantes e funcionários públicos para a organização de células na cidade e, assim, construir o partido nazista na região da mesma forma como foi feito em Santa Catarina. A partir de 1938, o registro da agremiação foi cassado pelo governo federal e posto na ilegalidade. Essa medida não despertou reclamação ou crítica, o que permite concluirmos que o Partido Nazista não estava enraizado na cultura política da cidade.

Os membros da elite local não simpatizavam com o nazismo como podemos perceber na pesquisa de Leandro Silva Telles (1980), que abordou a trajetória biográfica do médico e empresário local, Heinz Von Ortemberg. Esse integrante foi herói da Primeira Guerra Mundial. Estabeleceu residência em Santa Cruz, participou na construção da Mercur S/A., indústria de artefatos de borracha e foi o primeiro médico do Hospital Santa Cruz. Com a deflagração da Segunda Guerra, Ortemberg retornou para a Alemanha, para ser reincorporado ao Exército, porém a Gestapo, polícia secreta Nazista, possuía informaçóes sobre a atuação do médico em Santa Cruz e colocava em dúvida sua lealdade ao Exército alemão. Ortemberg passou por complicaçóes ao regressar à Alemanha e retornou ao Brasil com urgência.

Em minha pesquisa sobre o estudo prosopográfico (NORONHA, 2012), não foram encontrados integrantes da elite que possuíssem algum vínculo empresarial, familiar ou político com membros do partido nazista local. Mas, devemos ter cautela nessa conclusão. Não foram registrados nos obituários de Santa Cruz do Sul quaisquer vínculos com a ideologia nazista, pois isso representaria uma dificuldade nas negociaçóes políticas e econômicas em uma comunidade de imigrantes alemães no interior do Brasil. Dessa forma, dificilmente as fontes biográficas necrológicas 
revelariam alguma ligação dos indivíduos pesquisados com o nazismo. Schmidt avalia que a simpatia pelo nazismo por parte de setores da elite política brasileira teria influenciado o ambiente local, haja vista que o próprio contexto internacional estava marcado pela emergência de múltiplas ideologias ${ }^{3}$.

Em relação ao integralismo, René Gertz (1991) demonstra que esse grupo obteve grande sucesso no Rio Grande do Sul, principalmente nas regiôes de colonização alemã e italiana, pois seu lema "Deus, Pátria, Família", que foi cultuado pela Ação Integralista Brasileira, aproximou vários setores da Igreja Católica ao movimento.

De acordo com Schmidt (2004b), essa vinculação facilitou a penetração desse movimento na comunidade de Santa Cruz do Sul. Porém, a Ação Integralista Brasileira contando com núcleos em quase todos os distritos do município, não conseguiu eleger um só vereador, e seu candidato a prefeito nas eleiçóes de 1935, Dario Bittencourt, obteve pouco mais de 50 votos. $O$ perfil dos eleitores e simpatizantes da Ação Integralista Brasileira (AIB) tornava difícil sua massificação, pois ela era constituída por setores da classe média urbana, característica presente na comunidade local, pois a maioria dos encontros ocorria na Sociedade Ginástica, e a elite local tendia a frequentar o Clube União.

Em 1938, com a implantação do Estado Novo, a organização foi desmantelada, mas ressurgiu no Partido de Representação Popular (PRP), no período democrático-populista (1945-1964), com grande força política e eleitoral local. Schmidt avalia que o sucesso do PRP nas eleiçóes de Santa Cruz do Sul se explica pelo fato de que os antigos representantes da AIB abandonaram o discurso antidemocrático e aderiram ao processo de institucionalização. Essa adesão resultou no sucesso eleitoral desse partido, que o transformou na terceira força política da região. Assim, não podemos considerar conclusiva a tese de que a comunidade possuiria um alinhamento automático com organizaçóes de extrema direita. Outro fator que dissuadia a comunidade em relação à velha AIB foi seu forte discurso nacionalista. Este caso não atraiu grande aceitação em uma comunidade de

3 O período de 1918 até 1945 foi marcado por fortes transformações de ordem política que modificaram a dinâmica do mundo Ocidental; sobre o assunto ver parte um "A era das Catástrofes" em Hobsbawm ( 1996). 
imigrantes alemães. Já no contexto do PRP essas questóes foram superadas, pois tanto a comunidade deixou de atuar na defesa da identidade étnica quanto o partido abandonou seu forte teor nacionalista, o que contribuiu para sua afirmação na vida política local.

No campo da esquerda socialista ${ }^{4}$, Schmidt (2004c) afirma não encontrar organização partidária alinhada a III Internacional, como o Partido Comunista Brasileiro (PCB) ou Partido Socialista Brasileiro (PSB). Os dados eleitorais disponíveis dessas duas agremiaçóes na cidade, durante o período de 1945 até 1964, mostram que obtiveram inexpressiva votaçáo. Vale destacar que, mesmo com notas publicadas no jornal Kolonie a respeito de comemoraçóes pelo Dia Internacional do Trabalho ${ }^{5}$, a conjuntura da época não gerou clima favorável à formação de partidos de esquerda na vida política local. Na comunidade, a "ameaça comunista" foi diariamente explorada pelos integrantes da UDN de Santa Cruz, como o advogado Arthur Germano Fett, pai da escritora gaúcha Lya Luft, proprietário da residência que viria a se tornar sede do Sindicato da Indústria do Fumo. Na gestão presidencial de Eurico Gaspar Dutra (1945-1950), o PCB foi posto na ilegalidade, com manifestaçóes de apoio por parte da elite local contidas nas atas de reunióes da Câmara de Vereadores e da Associação Comercial e Industrial publicadas no jornal local.

Em relação à prática de uma cultura autoritária, Schmidt (2004c) avalia que a tendência de quebra da ordem democrática, somada à cultura autoritária brasileira, moldou a formação da cultura política local. Podemos afirmar que a reproduçáo dos posicionamentos da elite foi influenciada por esse padrão de relação política que ocorreu no âmbito nacional.

Para Silvana Krause, a primeira crise envolvendo a política nacional e a comunidade de Santa Cruz do Sul ocorreu durante a Primeira Guerra Mundial (1914-1918), período no qual as diferenças culturais do espaço

4 Schmidt identifica como esquerda socialista os partidos que, ao longo do período democrático ( 1945 - 1964), tinham forte aproximação com organizações sindicais, estudantis e de camponeses. Além disso, tinham alguma aproximação com o marxismo. Os principais partidos da esquerda socialista no período foram o Partido Comunista Brasileiro (PCB) e o Partido Socialista Brasileiro (PSB).

5 Pesquisadores que leram o jornal Kolonie encontraram reportagens de comemoração do $1^{\circ}$ de maio, Dia Internacional do Trabalho, com desfiles e bandeiras vermelhas pelas ruas da cidade na década de 1920. Mesmo com essa cultura, não vamos encontrar indícios de organização do sindicalismo internacional na comunidade. 
local entraram em colisão com o sentimento patriótico brasileiro que estava em vigor após a declaração de guerra:

A I a guerra mundial também gerou conflitos entre as zonas coloniais alemãs e o governo brasileiro. O rompimento das relações diplomáticas entre o Brasil e a Alemanha criou incidentes violentos em Porto Alegre (saques a empresas "alemãs", incêndios à sede de sociedades alemãs etc.), e em zonas do interior (fechamento de escolas, proibições da imprensa em língua alemã etc.) (KRAUSE, 2002, p. 172).

A partir da década de 1920, mediante uma estratégia de valorização da cultura nacional e de desregulamentação cultural das comunidades de imigrantes alemães e italianos posta em prática pelo governo federal, intensificaram-se as tensóes com práticas germânicas em vigor, como a língua escrita em jornais, o aprendizado do alemáo em escolas e a comunicação cotidiana nos estabelecimentos públicos e privados. $\mathrm{O}$ ápice foi durante a campanha de nacionalização de Getúlio Vargas, que proibiu a reprodução de qualquer documento ou manifestação que não tivesse um elemento valorativo do patriotismo brasileiro.

Schmidt (2004a) destaca um padrão comportamental muito recorrente nas disputas eleitorais tanto no interior quanto na sede. As eleiçóes foram marcadas por praticas de violência, ocorridas principalmente por meio de ameaças físicas, entre os integrantes da elite local. No contexto de análise, ocorreram uma tentativa de assassinato no início do século e um assassinato na década de 1960 com envolvimento direto de integrantes da elite local. Os fatos tiveram grande repercussão em âmbito estadual. Isso demonstra que a cidade não era tão pacata nas disputas locais. Nesse sentido, reproduzimos, de maneira comparada, os dois exemplos de maior repercussão na história política do município:

O primeiro, descrito por Silvana Krause (2002), foi a tentativa de assassinato de Carlos Trein Filho, considerado uma das figuras mais importantes da história política do município. Exerceu o cargo de diretor da Colônia de 1869 até 1872 e permaneceu com o título até 1881; foi vereador na primeira legislatura, em 1878; dedicou-se à Igreja Evangélica, ao Colégio Sinodal (atual Mauá) e foi um dos principais líderes da maçonaria 
local ${ }^{6}$. Sem dúvida, uma das figuras de maior influência política, cultural e econômica na comunidade. Na noite de 13 de junho de 1903, Trein foi atacado por três homens no momento em que se dirigia à loja maçônica. $\mathrm{O}$ político recebeu vários golpes de faca. Estes não chegaram a ser fatais, pois, de acordo com Krause, era uma noite muito fria e Trein usava um casaco grosso. O caso é um mistério até hoje, mas as suspeitas recaíram sobre a oposição, representada pelos integrantes do PRR (partido hegemônico no governo do Estado), visto que Trein, ligado aos Federalistas, aglutinou setores da oposição local.

O segundo ocorreu no início da década de 1960, quando o deputado estadual de Santa Cruz do Sul Euclides Nicolau Kliemann, do PSD, foi assassinado pelo vereador do PTB Floriano Peixoto Karan de Menezes. O deputado Euclides Kliemann era filho caçula do empresário João Nicolau Kliemann, integrante de uma das famílias mais tradicionais do setor de beneficiamento de fumo local. $\mathrm{O}$ crime ocorreu nas dependências da Rádio Santa Cruz, no meio de uma entrevista transmitida ao vivo entre as duas lideranças políticas. $\mathrm{O}$ fato repercutiu em âmbito estadual, pois vitimou um político conhecido que, naquele contexto, era uma das lideranças do PSD na Assembleia Legislativa.

Os fatos acima apontam, por um lado, a dificuldade de resolução pacífica dos conflitos e, por outro, demonstram que a elite de Santa Cruz do Sul tendia a estabelecer, ao longo do século XX, um padrão autoritário nas relaçóes sociais e políticas. De acordo com Schmidt (2003b), isso se explica pela tendência à quebra da normalidade democrática que era característica não apenas da comunidade, mas de toda a política nacional. $\mathrm{O}$ autor destaca que a comunidade sofreu com as interferências na vida política local promovidas pelos governos estaduais de Júlio de Castilhos e Borges de Medeiros, bem como com as arbitrariedades contra a população durante a campanha de nacionalização de Vargas. Esse quadro de repressão estadual, somado ao desapego da elite nacional por um padrão de comportamento

6 A maçonaria teve um peso político importante para a comunidade de Santa Cruz do Sul, em especial para o grupo filiado ao protestantismo. Em minha tese de doutorado (NORONHA, 20I2) e no trabalho de Krause (2002), foi realizado um estudo relacionando às redes de relações políticas e econômicas das principais famílias da cidade com a maçonaria. 
democrático, que ficou claro com o Golpe Militar de 1964, moldaram a cultura política da cidade.

\section{Negociação e cooptação do PRR na I República: a neutralização da cisão religiosa na política local}

A participação política da elite de Santa Cruz do Sul até a proclamação da República sempre foi problemática. Mesmo com o crescimento econômico da vila e a emergência de uma elite comercial e industrial, esse segmento esbarrava no obstáculo religioso para consolidar sua inserção política. Os empresários protestantes de Santa Cruz do Sul viviam em um espaço local com maioria católica, uma média de 55\% de católicos para $45 \%$ de protestantes, pouca variação, inseridos em um espaço regional e nacional com mais de $90 \%$ da população católica ${ }^{7}$. Para Krause (2002, p. 175), “[...] os imigrantes e colonos alemães filiados à religiâo luterana, em especial no período imperial, eram vistos como um perigo à fé católica professada pelo estado". Nesse contexto, intensificou-se o engajamento dos imigrantes alemães protestantes para ampliar seu espaço de atuação no campo político. Os evangélicos das regiōes de colonização encontraram no Partido Liberal alguns políticos que defendiam os acatólicos, como Gaspar Silveira Martins e Carl von Koseritz.

Krause (2002) observou que, durante o Império, ocorreu uma articulaçáo entre setores do PL e as lideranças políticas e empresariais da cidade. Esse grupo firmou negociaçóes para além da questão religiosa, em razão de interesses em comum. Esse tipo de aliança contribuiu para que fossem fortalecidas as relaçóes entre os integrantes da Loja Lessing, ligados à maçonaria e majoritariamente protestantes com o grupo católico. Esse contato permitiu a projeção do Major Frederico Guilherme Bartholomay (maçom e protestante) à política regional, pois ele foi o primeiro deputado provincial eleito por Santa Cruz do Sul.

7 Para maiores informações, Noronha (2012, p. II2) organizou o Gráfico 6 - Tendência da população católica e protestante de Santa Cruz do Sul entre 1849-1900 que reuniu dados sistematizados por Krause sobre a vida religiosa da cidade. 
A proclamação da República mudou radicalmente a relação entre a elite política protestante e o Estado brasileiro, pois a separação entre a igreja e o Estado permitiu ampliar o peso político desse segmento. Vale destacar que esse grupo se beneficiaria, de um lado, pelo nível de escolaridade de sua população e, por outro, pela emergência de uma classe média urbana e industrial.

A reação dos católicos com a separação entre a Igreja e o Estado, promovida pela Proclamação da República, resultou na criação de um partido com a finalidade de unir diferentes grupos com interesses em comum. Em maio de 1890, os jesuítas gaúchos fundaram o Partido do Centro Católico, antes da promulgação da nova constituição republicana que entraria em vigor após 1891. No entanto, essa agremiação teve vida curta, pois os jesuítas superestimaram o apoio que receberiam dos pecuaristas católicos da metade sul e dos empresários católicos das regióes de colonização. Isso ocorreu justamente pela própria identidade existente entre a igreja e o império, fazendo com que a elite agrária católica e os comerciantes da mesma religião aderissem ao PRR, o que ocorreu na cidade de Santa Cruz a partir de 1900 .

Em meu trabalho de doutorado, Noronha (2012, p. 91) reúno, no banco de dados eleitorais de Santa Cruz do Sul, as votaçôes de 1891, 1896, 1897 e 1900 para os cargos de âmbito local na disputa envolvendo o PRR e o Partido do Centro Católico. Analisando a dinâmica dessas duas agremiaçóes entre 1891 até 1900 , percebemos que o PRR oscilou de maneira mais intensa, chegando a uma mesma eleição, a de 1896, a ter 66\% de votos para seus vereadores e 23,20\% para intendente. O Centro Católico manteve uma relativa estabilidade, pois conseguiu reunir, em nove anos de atuação, um eleitorado convicto até sua extinção em 1900, sendo cooptado pelo PRR, que se beneficiaria na disputa eleitoral com o PL (que nessa época era Federalista, mas manteve-se registrado no banco de dados eleitorais de Santa Cruz como PL, na maioria protestante) nas eleiçóes de 1897 , quando alcançaria mais de $80 \%$ dos votos, em um contexto em que o PRR estava cooptando lideranças católicas e protestantes da cidade 8 .

8 Para maiores informações, consultar a "Tabela 2 - Relatório eleitoral comparado entre o PRR e o PCC" e o "Gráfico 2 - Desempenho eleitoral do PRR e do PCC em Santa Cruz ( 189 I- 1900)" em Noronha (2012, p. 91-92) que 
Krause (2002) afirma que a elite local procurava estabelecer uma relação de autonomia frente ao Partido Republicano Rio-Grandense. Com isso, visava a garantir cargos para seus representantes sem uma adesão incondicional. Mesmo assim, as relaçóes entre PRR e a elite de Santa Cruz do Sul foram tensas, o que permite observar uma cautela desse segmento em abandonar as agremiaçôes ligadas aos Federalistas (antigo PL) e o PCC no período da I República.

Entendemos que o PRR adotou, nos primeiros anos da República em Santa Cruz do Sul, uma política de "cooptar" ou formar algumas lideranças naturais da localidade, isto quando não conseguia indicar um "funcionário" ao lugar. Neste sentido, o Partido do Centro Católico cumpria um papel importante na medida em que possibilitou em alguns momentos uma aglutinação de forças locais para não permitir o fortalecimento maior dos federalistas (pois o Partido do Centro Católico tinha seus quadros políticos naturais de Santa Cruz do Sul). (KRAUSE, 2002, p. 149).

Avaliamos que, no início da vila, o partido que melhor representaria os interesses dos empresários protestantes no contexto do Império era o Partido Liberal, nas figuras de Silveira Martins e Koseritz (ambos maçons e anticlericais). No banco de dados eleitorais de Santa Cruz do Sul, durante a I República essa agremiação continuaria a ser registrada com a mesma sigla, mas sabemos que foi reconhecido como Partido Federalista e teve como principal líder local o comerciante Carlos Trein Filho, que aglutinou toda a oposição ao PRR naquele contexto, sendo vítima de um atentado em 1903. Comparamos a atuação do PRR e do PL na cidade de Santa Cruz do Sul. Conseguimos levantar os dados eleitorais de 1896, 1897, 1900, 1922 e 1924 para cargos de âmbito local e regional.

Percebemos que o PL perdeu espaço eleitoral na medida em que o PRR cooptou lideranças protestantes ligadas aos Federalistas. Esse partido iniciou com 23,20\% nas eleiçóes de 1896 e ampliou seu percentual para 37\% nas eleiçóes para vereador do ano seguinte. Nas eleiçốes de 1922 e 1924, conseguiu mais de $80 \%$ dos votos ${ }^{9}$. Segundo Love (1975), a oposição ao

ilustram a dinâmica eleitoral entre as duas agremiações. Lançamos mão do Banco de Dados Eleitorais de Santa Cruz do Sul.

9 Para informações adicionais, a Tabela 3 - Relatório eleitoral comparado entre PRR e PL em Noronha (2012, p. 93) traz informações de cada eleição entre os anos citados. A fonte utilizada foi o Banco de Dados Eleitorais de Santa Cruz do Sul. 
PRR era forte nas regióes da fronteira, mas era muito fraca na zona colonial alemã e italiana, fato que garantiu a vitória de Castilhos na Revolta Federalista. O quadro eleitoral de Santa Cruz do Sul comprova essa tendência; após 1897 o PRR manteve sua hegemonia na política local, conseguindo vencer todas as disputas com o PL, que aglutinava os Federalistas.

Para Pedro Dutra Fonseca (1983), a trajetória da oposição gaúcha é bem mais complexa em comparação com os outros estados da federação, pois se pode afirmar que ela descende do PL, dominante no Rio Grande do Sul nas últimas décadas do Império. Vale destacar que Krause aponta esse partido como o mais forte na Vila de Santa Cruz, pois foi de lá que emergiram nomes como o de Frederico Guilherme Bartholomay. Fonseca (1983) destaca que, uma vez proclamada a República, o PRR ganhou adeptos monarquistas, especialmente do Partido Conservador. O campo majoritário do PL, ainda sob a orientação de Gaspar Silveira Martins, passou à oposição com a nova sigla: Partido Federalista, registrado no banco eleitoral de Santa Cruz como PL.

Em relação à disputa eleitoral entre os partidos com alguma identidade religiosa, conseguimos reunir os resultados das eleiçóes de 1896, 1897 e 1900 para os cargos de âmbito local, comparativamente, o desempenho do Partido do Centro Católico e do Partido Liberal nessas três eleiçóes.

Em meu trabalho (NORONHA, 2012, p. 94), observei que os dois partidos tendiam a cair até 1900 , tendo em vista a estratégia bem-sucedida do PRR de cooptar os líderes das duas forças políticas. Mas, comparando somente a disputa entre o PL (com maioria protestante) e o PCC (católico), percebemos que o primeiro teve uma queda mais expressiva. Isso não significa que os protestantes tivessem perdido espaço político local; bem pelo contrário, encontraram no PRR poder de barganha para uma atuaçáo política mais sólida em comparação com a agremiação representada por Carlos Trein Filho e que havia sido derrotada na Revolta Federalista ${ }^{10}$.

I0 Para maiores detalhes quanto aos números de cada eleição, consultar a "Tabela 4 - Relatório eleitoral comparado entre PCC e PL" e o "Gráfico 4 - Desempenho eleitoral do PCC e do PL em Santa Cruz (1896-1900)" em Noronha (2012 , p. 94) com base no banco de dados eleitorais de Santa Cruz do Sul. 
Na medida em que o PCC e o PL perdiam força eleitoral, tendo em vista a consolidação da separação entre igreja e Estado, provocou progressivo esvaziamento do discurso ideológico que foi assentado no interesse religioso. Krause (2002) aponta para uma articulaçáo mais acentuada entre protestantes e católicos para barganhar interesses políticos e econômicos comuns via PRR. Analisado a filiação religiosa dos vereadores de Santa Cruz do Sul, ao longo de 1905 até 1966, percebemos que a maioria foi filiada à religiáo protestante, mas isso nunca foi considerado um empecilho nas relaçóes sociais.

Para os protestantes seria fundamental obter um nível de articulação política com a comunidade católica, pois esse grupo possuía um canal de negociação com o governo estadual. Exemplo disso ocorreu em 1915, quando os empresários do fumo, majoritariamente protestantes, receberam uma carta de recomendação feita pelo intendente municipal Galvão Costa, na época indicado pelo PRR e filiado ao catolicismo, para uma reunião com o governador Borges de Medeiros na capital estadual, Porto Alegre:

São portadores desta os adiantados industrialistas aqui estabelecidos João Nicolau Kliemann, José Carlos Kohmann, Adolfo Iserhard, José Etges Filho, Theodoro Schilling, Guilherme Presser, Helmuth Schütz, os quais desejam entender-se pessoalmente com V. Exa. sobre assunto de grande relevância para Santa Cruz que diz respeito ao seu mais importante fator de riqueza econômica local, o fumo. (INSTITUTO HISTÓRICO GEOGRÁFICO DO RIO GRANDE DO SUL. Correspondência de Galvão Costa a Borges de Medeiros em 13.01.1915.? apud KRAUSE, 2002, p. 149).

Podemos observar que a reunião tinha como pauta a criação de uma grande indústria de cigarros de capital nacional, a Cia. de Fumos Santa Cruz S/A, que seria fundada por esses integrantes da elite local em 1918; além disso, comentaram sobre os planos de fundar uma Associação Comercial e Industrial e trataram da possibilidade da filial da British American Tobacco (B.A.T.) se instalar na cidade. Vale destacar que na época a empresa estava indecisa entre Rio Pardo e Santa Cruz, mas, tendo em vista do potencial da agricultura familiar e da disponibilidade de recursos para a instalaçáo da empresa estrangeira na cidade, Santa Cruz acabou recebendo-a em 1917. Assim, o empresariado local possuía no PRR um canal de negociação política com o poder público estadual. 
Podemos afirmar que o contexto da I República foi importante na medida em que neutralizava uma cisão político-religiosa que havia na comunidade de Santa Cruz na época do Império. A separação do Estado e da Igreja Católica, combinada com a progressiva estratégia de cooptaçáo dos integrantes da elite local pelo PRR, ligada aos dois grupos, fez recrudescer essa polarização. Os resquícios de divergências entre católicos e protestantes na política local foram desregulados após a Revolta Federalista. Para os protestantes, a adesão ao PRR significou a abertura de um canal de diálogo com o poder público central, enquanto que para os empresários católicos esse partido representava o perfil de um novo regime que havia deposto a Monarquia.

\section{A elite local frente ao conservadorismo e continuísmo no pós- 1930}

Em relação à Revolução de 1930, ficou evidente, a partir da análise das fontes biográficas e empresariais, a apreensão quanto aos resultados desse conflito na vida política e econômica da cidade. A frente única, liderada pelo governador Getúlio Vargas, conseguiu neutralizar as históricas divergências que ainda existiam no Rio Grande do Sul que foram ocasionadas por duas revoltas: a de 1893-95 e a de 1923. Silvana Krause (1991, p. 183) observou, em uma reportagem do jornal Kolonie, a adesão de várias entidades da comunidade na revolução de 1930 :

O povo deste município, compenetrado da grandeza extraordinária da causa que empolga o Rio Grande do Sul e a Pátria, resolveu organizar, sem distinções de cores partidárias, uma junta revolucionária com o escopo de dar maior eficiência no concurso de Santa Cruz do Sul ao movimento sagrado da Redenção da Pátria, no momento em que se decide o seu destino. Patriotas de Santa Cruz do Sul! O Rio Grande com o seu pró-homens à frente confia no vosso auxílio. Parafraseando a resposta que o presidente do Estado, Dr. Getúlio Vargas, deu ao major Plínio Tourinho [...] deveis bradar com os que já estão se batendo pela regeneração da República. Bravo! Marchamos com o Rio grande ao vosso encontro, vamos todos, Exército e Povo. Vinde juntar os vossos nomes aos daqueles que já se acham inscritos na lista dos voluntários que vão pagar o seu tributo no campo da honra [...]. Santa Cruz, 9 de outubro de 1930. A Junta Revolucionária. José W. Koelzer, Gaspar Bartholomay, Artur G. Fett, Guilherme Hildebrandt, Alfredo Ludwig, Felipe Jacobus Filho, Fernando Werlang, Pedro Corrêa, F. C. Tasch, Ricardo Hoffmann Filho, Artur Jäeger, Marciano L. Ferreira, João C. Frantz, Adão Bapp, Leopoldo Strohschöen e Mario Carneiro. "I

II Trecho extraído do Jornal Kolonie, dia 10 de outubro de 1930 (KRAUSE, 2002). 
Krause afirma que vários integrantes da elite de Santa Cruz do Sul apoiaram o movimento liderado por Getúlio Vargas, mas esse apoio não foi tão explícito. Por exemplo, no processo de implantação do regime republicano em 1889, em que as diferenças religiosas poderiam contribuir para um clima de polarização entre os adeptos do novo regime e os apoiadores do antigo.

João Pedro Schmidt (2004b) aponta que se a adesão ao movimento de 1930 foi ampla nos setores empresariais e político local, não foi tranquila na vigência do governo de Getúlio Vargas até 1945. Nesse período, importantes transformaçôes ocorreram na sociedade brasileira, como a urbanização e a industrialização. Esse processo fundou a formação de uma nova identidade nacional que entrou em choque com a cultura comunitária das regiões de colonização alemã e italiana no interior do estado. A assimilação forçada, orquestrada pelo Estado brasileiro, de maneira progressiva após a Primeira Guerra Mundial, intensificou-se com Vargas. Isso foi um duro golpe nas relaçóes entre o governo federal e a comunidade. O ápice dessa crise foi, sem dúvida, a Segunda Guerra Mundial, quando o Brasil novamente entrou em guerra contra a Alemanha, e, de acordo com Eric Hobsbawm (1996), as questóes étnicas estavam mais intensas nesse conflito do que o período anterior, a Primeira Guerra, marcado por disputas de mercado.

O contexto da Segunda Guerra atingiu todos os setores da economia e da política local. Este desconforto pode ser retratado pelo posicionamento da Associação Comercial e Industrial de Santa Cruz do Sul nos períodos de 1942 até 1944:

[...] foi proposto e achado bom que, no próximo boletim mensal, se fizesse um apelo ao comércio, às indústrias e a toda população para que conservassem suas casas embandeiradas durante os festejos da Semana da Pátria e outros feriados nacionais para não deixar dúvidas sobre o patriotismo santa-cruzense [...]. (CADONÁ, 2002, p. 55)"12.

Vale destacar que, a partir de 1945, o comportamento político local foi influenciado pelas mudanças que ocorreram por meio da implantaçáo

12 Trecho extraído da Ata de reunião da diretoria da $A C l$ n 10, de 09 de julho de 1942 (CADONÁ, 2002). 
do regime democrático no Brasil pós-Vargas. Percebemos, pela primeira vez, que foi consolidado um discurso político de maneira democrática durante as eleiçóes de Santa Cruz do Sul. Fato que anteriormente não era discutido de maneira explícita, pois a publicidade eleitoral era canalizada pelo "Coronel" e não para a defesa de um regime.

Esse quadro influenciou o comportamento da elite local, visto que o pós-Segunda Guerra acabou gerou transformaçôes na política nacional ${ }^{13}$. Com o fim do Estado Novo, ocorreram a organização de vários partidos e o retorno às eleiçóes dentro de uma normalidade democrática estável. Havia pluripartidarismo, eleiçôes organizadas e reguladas pela Justiça Eleitoral. Na verdade, foi a primeira vez que o Brasil passou por uma conjuntura de relativa estabilidade, durante duas décadas, interrompida pelo Golpe de 1964. Na cidade de Santa Cruz do Sul se estruturaram os seguintes partidos: Partido Social Democrático (PSD), Partido da Representação Popular (PRP), Partido Libertador (PL), União Democrática Nacional (UDN), Partido Trabalhista Brasileiro (PTB) e Partido Comunista do Brasil (PCB).

Este último teve seu registro cassado em 1947. Apesar da frágil estrutura democrática brasileira, essa experiência teve resultado significativo, pois enraizou culturalmente o conceito de "democracia", tanto nos discursos da elite nacional quanto da elite local ${ }^{14}$. João Pedro Schmidt mensura, através dos resultados eleitorais em diferentes momentos da política brasileira, as variáveis "conservadorismo" e "continuísmo" na prática da cultura política local. Ele comparou os grupos políticos que estavam no poder executivo e legislativo de Santa Cruz do Sul. O autor afirma que o bloco conservador manteve-se hegemônico no quadro geral das eleiçôes para a prefeitura tan-

I3 O pensamento político mudou com o fim da Segunda Guerra. Figuras como Getúlio Vargas, que simpatizavam com o fascismo, passaram a adotar uma postura democrática. Mesmo que esse processo fosse conturbado pela luta contra o comunismo, é inegável que o engajamento da elite ocidental girava em torno do fortalecimento e da defesa da democracia. Pelo menos entre 1945 até a Revolução Cubana de 1959, era regra na América Latina. Outro fator de mudança da ordem cultural foi a expansão da rede telefônica, do rádio e da televisão. Esses instrumentos deram os primeiros passos para a cultura global e de massa. Isso viria a influenciar diretamente a cultura do consumo do cigarro, que era benéfico para a indústria fumageira de Santa Cruz do Sul.

14 Esse foi talvez o grande mérito do período de 1945 até 1964. Mesmo com sua fragilidade, a cultura de respeito às instituições começou a ganhar corpo. Todos os eventos que ocorreram no pós-Estado Novo tinham como justificativa preservar a "ordem democrática”; inclusive o próprio Golpe de 1964 era chamado de "Revolução Democrática". 
to no período democrático (1945-1964) quanto no regime militar (19641985). Por outro lado, no que tange às eleiçóes para governador e para a presidência, o campo progressista teve significativa votação, mesmo com a elite política local pertencendo majoritariamente ao bloco conservador.

Schmidt (2004c, p. 3) demonstra que o continuísmo não fez parte da trajetória eleitoral da comunidade, pois a tendência que encontramos entre 1945 e 1964 foi de hegemonia do bloco conservador e de progressivo deslocamento do voto para a oposição nas eleições majoritárias (presidente, prefeito, senador e governador). Após o Golpe de 1964, ocorreu a mesma tendência: a concentração hegemônica do conservadorismo no início e a progressiva transferência de votos para a oposição ${ }^{15}$.

João Pedro Schmidt (2004c) analisou o desempenho dos partidos políticos no contexto democrático-populista (1945-1966) em Santa Cruz do Sul e encontrou um padrão de semelhança no desempenho do PTB e PSD na escala nacional. O autor destaca que, nas eleiçôes locais, havia uma hegemonia acentuada do PSD na fase inicial e um progressivo crescimento eleitoral do PTB, combinado com a emergência da UDN, que acabaria se alinhando ao PSD até o Golpe de 1964. O dinamismo eleitoral de 1945 até o AI-2, implantando em 1965, acompanhou com certa semelhança o padrão de evolução na escala regional e nacional. A tabela, apresentada seguir, feita por Schmidt (2004a), permite visualizar o desenvolvimento dos partidos ao longo dos anos de 1947-1982 na Câmara Municipal de Vereadores.

I5 Para maiores detalhes consultar a "Tabela 5: Voto na situação e na oposição - 1945-1964" em Noronha (2012, p. 99) que reúne informações coletadas e sistematizados por Schmidt no Banco de Dados Eleitorais de Santa Cruz do Sul. 
Tabela I - Vereadores eleitos por campo ideológico - 1947-1982*

\begin{tabular}{|c|c|c|c|c|}
\hline \multirow{2}{*}{$\begin{array}{l}\text { Ano } \\
1947\end{array}$} & \multicolumn{2}{|c|}{$\begin{array}{c}\text { Partidos Liberal- } \\
\text { Conservadores }\end{array}$} & \multicolumn{2}{|c|}{$\begin{array}{l}\text { Partidos Populista } \\
\text { Progressistas }\end{array}$} \\
\hline & PSD & 09 & PTB & 01 \\
\hline & $P L$ & 02 & & \\
\hline & PRP & 01 & & \\
\hline \multirow[t]{3}{*}{1951} & PSD & 05 & PTB & 05 \\
\hline & $P L$ & 02 & & \\
\hline & PRP & 01 & & \\
\hline \multirow[t]{3}{*}{1955} & PSD & 05 & PTB & 04 \\
\hline & $P L$ & 02 & & \\
\hline & PRP & 02 & & \\
\hline \multirow[t]{4}{*}{1959} & PSD & 04 & PTB & 05 \\
\hline & PL & 02 & & \\
\hline & PRP & 01 & & \\
\hline & PDC & 01 & & \\
\hline \multirow[t]{3}{*}{1963} & PSD-UDN & 06 & PTB & 03 \\
\hline & PDC & 01 & & \\
\hline & PL & 01 & & \\
\hline 1968 & Arena & 10 & MDB & 03 \\
\hline 1972 & Arena & 11 & MDB & 06 \\
\hline 1976 & Arena & 10 & MDB & 09 \\
\hline \multirow{2}{*}{1982} & \multirow{2}{*}{ PDS } & \multirow{2}{*}{10} & PMDB & 09 \\
\hline & & & PDT & 02 \\
\hline
\end{tabular}

* Informações extraídas do Banco de Dados Eleitorais de Santa Cruz do Sul. Fonte: Schmidt (2004a, p. 8).

Schmidt identificou uma tendência de predomínio do PSD e sua progressiva queda no contexto democrático. Esse grupo iniciou com nove vereadores, sendo a maior bancada no processo eleitoral pós-Vargas. Nas eleiçóes de 1951, registrou-se um aumento extraordinário do PTB, que saltou de um para cinco vereadores; e, no mesmo período, Getúlio Vargas se preparou para retornar à Presidência da República. Isso pode ter contribuído para o aumento eleitoral desse partido na cidade. O PSD perdeu 
quase metade dos nove vereadores, com cinco no pleito de 1951, e manteve essa tendência até a promulgação do Ato Institucional no 02 , enquanto que o PTB obteve um crescimento expressivo, chegando a ser a maior bancada em $1959^{16}$.

Certamente o assassinato do deputado estadual Euclides Kliemann, do PSD, por um vereador do PTB contribuiu para a queda desse partido nas eleiçôes de 1963; além disso, a UDN local firmou aliança com o PSD em 1963, deslocando seu peso eleitoral com sua cruzada "antiGoulart". O envolvimento do presidente da República na defesa do vereador do PTB repercutiu mal, pois João Goulart pagou a defesa de Karan de Menezes, contratando o advogado Pedro Simon. Este iniciou sua carreira política pelo PTB e também se tornou uma das principais lideranças do MDB no período da ditadura, chegando a ser governador estadual no período democrático pós-1985.

A tendência que encontramos na formação política local foi de adesão aos grupos políticos hegemônicos em âmbito estadual e nacional. É exatamente por meio desses casos que temos como pretensão a compreender se essa elite possuiu a capacidade de manter a unidade política em um contexto de crise entre o governo estadual e nacional. O período de 1961 até 1964 é interessante para entendermos a capacidade de negociação local frente às crises institucionais.

\section{A elite local frente à crise de âmbito regional/nacional: o caso da Legalidade e do Regime Militar, 1961-1965}

Observando os noticiários do principal jornal do município, Gazeta do Sul, percebemos que a década de 1960 foi tumultuada na vida política local, pois ocorreram dois fatos que levaram a elite de Santa Cruz do Sul a tomar posiçóes contraditórias em um espaço relativamente curto de tempo: o movimento pela Legalidade, liderado pelo governador Leonel Brizola, que tinha como objetivo garantir a posse do presidente João

I6 Em Noronha (2012, p.I0I) o Gráfico 5 - Dinâmica eleitoral dos partidos na Câmara Municipal de Santa Cruz do Sul, 1947-1963 ilustra a tendência de cada agremiação partidária com base no Banco e Dados eleitorais de Santa Cruz do Sul. 
Goulart, e a implantação do regime militar após o Golpe de 1964. Essa contradição permite observarmos que a prioridade desse segmento foi a manutenção da integridade da cidade em uma eventual guerra civil.

Entre os meses de agosto e setembro de 1961 a conjuntura nacional se desestabilizou. A renúncia de Jânio Quadros, poucos meses depois da posse, não chegou a causar preocupação entre a elite de Santa Cruz do Sul, mas o engajamento do então governador do Estado, Leonel Brizola, em conjunto com o comandante do III Exército, com sede em Porto Alegre, liderando a campanha pela Legalidade, forçou esse segmento a atuar no apoio ao processo sucessório, embora João Goulart e Brizola fossem do PTB, partido de oposição local.

A Prefeitura Municipal de Santa Cruz do Sul, apreensiva com os rumos que vêm tomando os acontecimentos, dentro da crise determinada pela surpreendente renúncia do Presidente Jânio Quadros, vem fazer o seu pronunciamento pela legalidade em prol da integridade da ordem constitucional. Como sucessor legal do presidente renunciante deverá assumir a presidência da república o Dr. João Goulart, e como expressão legítima do poder civil da República, é do seu dever esclarecer o povo brasileiro sobre as verdadeiras causas do afastamento do presidente tão expressivamente consagrado pelas urnas de 1960. [...] Se, todavia, ao revés, ficasse constatado que a renúncia do Dr. Jânio Quadros foi ato de sua espontânea determinação e atitude livremente assumida, então estaremos aqui para afirmar ao Dr. João Goulart a nossa solidariedade de democratas e a nossa colaboração de brasileiros, prontos a prestigiar todas as suas iniciativas que visem ao progresso do País. Santa Cruz do Sul, 28 de agosto de $1961^{17}$.

A adesão da elite ao movimento pela Legalidade mostrou uma ação política voltada para a defesa do espaço local, refletindo assim seu forte caráter comunitário. Nesse artigo, podemos visualizar o posicionamento da Câmara de Vereadores no mesmo dia:

Em reunião permanente desde sexta feira última, acompanha apreensiva e perplexa o desenrolar dos acontecimentos surgidos com a renúncia de sua Ex. ${ }^{a}$ o Presidente da República Sr. Jânio Quadros.

Pela unanimidade de seus membros manifesta suas convicções democráticas pela defesa da legalidade, e pela manutenção das prerrogativas constitucionais e livre exercício dos mandatos pelos governantes eleitos pela vontade soberana do povo brasileiro.

17 Trecho extraído de Gazeta do Sul, 29 de agosto de 196I, p.I. 
Lança veemente protesto contra as tentativas para subversão da ordem constitucional e consequentemente implantação do regime de força, contrariando assim a vontade soberana do povo brasileiro manifestada através das urnas livres.

Apela ao povo santa-cruzense no sentido de que se mantenha sereno e unido, confiando no patriotismo e convicções democráticas dos responsáveis pelos destinos da Nação.

Santa Cruz, 28 de agosto de 1961.

Elemar Gruendling - Presidente. ${ }^{18}$

Nessa ocasião a bancada do PTB era a maior na Câmara Municipal, com cinco vereadores, mas o apoio ao movimento pela Legalidade náo representaria um posicionamento favorável a João Goulart ou Brizola. $\mathrm{Na}$ pesquisa de Cadoná (2002) constatamos que a elite local sempre esteve majoritariamente representada por agremiaçóes de caráter conservador, estando ligada ao bloco PSD/UDN durante o período democrático-populista.

Para Skidmore (1988), se dependesse da maioria da classe política no Congresso Nacional da época, ou dos governadores e outras agremiaçôes partidárias, Goulart não assumiria o poder em setembro de 1961. Esses mesmos setores estiveram, com certeza, representados politicamente na cidade de Santa Cruz do Sul, e o apoio à legalidade aconteceu porque o governo gaúcho e o III Exército estavam engajados e determinados a travar o conflito armado.

Anteontem, quinta-feira, no recinto da Câmara de Vereadores desta cidade, por iniciativa do Dr. Arno Schmidt, devidamente credenciado pelo deputado Milton Dutra, como o Coordenador local do Comitê Pró-Resistência Democrática, reuniram-se os membros do legislativo santa-cruzense, vereadores Elemar Gruendling, Ottomar Muench, Dr. Luiz A. Jacobus, Floriano P. Karan Menezes, Júlio de Oliveira Viana, Querino Pereira de Aquino, Dr. Patrick Francis Fairon, Lindolfo Spengler, Harry Werner e José Alvino dos Santos, o Dr. Arno Schmidt, o Sr. Edmundo Hoppe, Prefeito Municipal, Deputado Norberto H. Schmidt, Dr. Arthur G. Fett, Carlos Edmundo Steffens, Carlos Mauricio Werlang, Sebaldo Kroth, Carlos Hoppe, Arno Frantz, Roque Coimbra, Roberto Hartungs, Waldomiro Gil, Jürgen Klemm, Milton Nagel, Lothário Bartholomay, e dezenas de outras pessoas gradas da cidade. ${ }^{19}$

A criação do Comitê, além de mostrar o nível de engajamento local, permite visualizar a capacidade de construçáo de um posicionamento

I8 Gazeta do Sul, ano 17, n 103, 29 de agosto de 1961, p. 2.

19 Gazeta do Sul, ano 17, n 105, 02 de setembro de 196I, p.I. 
homogêneo frente aos acontecimentos nacionais. Outros estudos apontam para essa tendência: Carina Martiny (2010) ao tratar da elite de São Sebastiāo do Caí durante a transição do Império para a República, em 1889, e Silvana Krause (2002) ao se ocupar com o caso de Santa Cruz. Outro exemplo foi a Revolta Federalista de 1893-1895; embora polarizasse a elite gaúcha, permite observar um comportamento da elite local visando a manter a vila na neutralidade ${ }^{20}$. Esse quadro reforça a hipótese de que o empresariado de Santa Cruz do Sul negociava para garantir a estabilidade local, embora isso estivesse em divergência com seus reais interesses ou posicionamentos ideológicos. Buscava neutralizar e homogeneizar as posições para não abrir fissuras que pudessem desestabilizar sua rede local.

Abertos os trabalhos pelo Sr. Presidente da Câmara de Vereadores, explicou sua Senhoria os motivos da reunião bem como fez explanações sobre a atual situação política quando o Rio Grande do Sul, pela pessoa de seu ilustre governador se levantou e se mantém em defesa da constituição federal e da ordem legal. Em seguida passou a palavra ao Dr. Arno Schmidt, que comunicou, preliminarmente, ter recebido do Deputado Milton Dutra, Coordenador Geral, em todo o Estado, dos comitês pró-resistência democrática, um ofício credenciando-o como coordenador local do referido comitê para a defesa democrática do país e consequentemente da posse do vice-presidente Dr. João Goulart. O comitê local deveria receber inscrições de voluntários e da constituição de uma guarda. Explicando, também, que o movimento era despido de qualquer intenção ou interesses partidários, era de congraçamento de todos os partidos políticos em defesa da Legalidade. O Dr. Luiz Jacobs sugeriu, logo após, um serviço de doação de sangue. Falou ainda o estudante Jürgen Klemm, presidente da UESC, lendo um manifesto daquela União de Estudantes em favor da preservação da constituição federal. Falaram ainda os senhores Ottomar J. Muench, Floriano P. Karan Menezes, Júlio de Oliveira Viana, Querino Pereira de Aquino, Harry Werner e Dr. Patrick F. Fairon, todos se solidarizando com a formação do comitê. ${ }^{21}$

Outras instituições marcaram presença na defesa da Legalidade, como o jornal Gazeta do Sul, que teve como principal representante Francisco José Frantz (diretor do jornal e diretor da ACI na década de 1960). A União dos Estudantes de Santa Cruz do Sul (UESC) foi representada pelo estudante Jürgen Klemm, presidente da entidade e futuramente empresário do setor de alimentos. Ele investiu na carreira política, se tornou

\footnotetext{
20 O empresário do ramo do fumo Theodoro Schilling conseguiu arregimentar uma força local que objetivava manter a Vila de Santa Cruz "neutra" no conflito durante a ocupação serrana em 1893.

21 Gazeta do Sul, ano 17, n 105, 02 de setembro de 196I, p.I.
} 
vereador pelo Partido Democrático Cristão (PDC) e, depois pela Aliança Renovadora Nacional (ARENA). Assumiu também a direção da ACI, construindo assim um modelo de trajetória que foi descrito por Wright Mills em seu estudo da elite de cidades pequenas dos EUA'

Havendo, assim, identidade de pontos de vista, quanto à criação do comitê local pró-resistência democrática, o presidente dos trabalhos submeteu à apreciação dos presentes a organização do comitê local pró-resistência democrática, o presidente dos trabalhos submeteu à apreciação dos presentes a organização do Comitê. Com todos os presentes como componentes, o que foi calorosamente aplaudido. Foi organizada a diretoria que, por aclamação, ficou assim constituída:

Presidente: Dr. Arno W. Schmidt

Vice-Presidente: Dr. Patrick F. Fairon, Sebaldo Kroth, Ottomar J. Muench, Roberto Hartungs e Jürgen Klemm.

$1{ }^{\circ}$ Secretário: Floriano Peixoto Karan Menezes

$2^{\circ}$ Secretário: Carlos Hoppe

$1^{\circ}$ Tesoureiro: Carlos Edmundo Steffens

$2^{\circ}$ Tesoureiro: Roque Coimbra

Com. de Propaganda: Lothario Bartholomay e Francisco Frantz. ${ }^{23}$

Apesar de não ter ocorrido o pior, uma guerra civil, esse fato merece ser destacado, pois deixa clara a unidade e a capacidade de negociação da elite local frente a crises envolvendo o governo estadual e federal. Os mesmos integrantes da elite local que apoiaram o movimento pela Legalidade, em agosto/setembro de 1961, apoiariam o Golpe de 1964, aderindo ao Regime Militar, reforçando a tese de que em crises nacionais a elite local aderia ao grupo hegemônico.

22 Para Mills, as cidades médias ou pequenas dos Estados Unidos da primeira metade do século XX possuem grupos de famílias distintas do restante da comunidade, pois controlam a produção majoritária da riqueza e formam a opinião pública local. Esse grupo é constituído pelos proprietários e editores da imprensa, tanto de jornais quanto de emissoras de rádio, fato que encontramos na análise biográfica dos empresários de Santa Cruz do Sul no mesmo contexto. Mills revela que, além do capital simbólico ou cultural, o principal ponto de distinção, prestígio e manutenção da posição social de uma elite local é o controle do capital econômico, visualizado através dos seus estabelecimentos comerciais, localizados na rua principal da cidade; das indústrias, que, normalmente, são as maiores no município; e na direção das sociedades anônimas de capital aberto que se constituem localmente, pois esse grupo é acionista majoritário desses empreendimentos. $O$ autor infere que essa condição foi moldada, progressivamente, através do convívio coletivo comum, mais homogêneo e antropologicamente próximo, condição facilitada numa escala local ou provinciana. Sobre o assunto ver o segundo capítulo de "MILLS, C. Wright. A elite do poder. Tradução de Waltensir Dutra. Rio de Janeiro: Zahar Editores, 1965". 
Jorge Ferreira (1997) destaca que o apoio de vários setores da elite brasileira a João Goulart deve-se ao formalismo e a legalidade do processo. $\mathrm{O}$ autor destaca que os golpistas como o governador da Guanabarra, Carlos Lacerda, e o núcleo duro das forças armadas perderam força pela simples razão de que praticaram atos ilegais. No caso da mobilização da elite local e regional na Legalidade e em perspectiva comparada ao Golpe de 1964, percebemos um padrão de adesão ao legalismo. Cadoná (2002) destaca que, no dia seguinte à derrubada de João Goulart, todas as agremiaçôes partidárias, as associaçóes e os sindicatos manifestaram seu apoio aos militares. Esse apoio veio após as turbulentas manifestações ilegais que ocorreram no início de 1964 e não foram reprimidas por Goulart, que perdeu a chamada "moral legalista" que levou a unidade dos militares e da elite brasileira a derrubá-lo em 31 de março daquele ano.

A repressão às reivindicações trabalhistas e o controle da inflação por meio de repressão aos movimentos populares foram as principais razóes que fizeram a elite local aderir ao regime. Esse apoio ficou evidenciado na análise dos noticiários veiculados pelo jornal Gazeta do Sul nos primeiros anos de comemoração do regime:

$1{ }^{\circ}$ Aniversário da Revolução Democrática: Foram brilhantes os festejos / Foi realizado ontem 3 | de Março, a festa do $1^{\circ}$ aniversário da revolução democrática, onde foi realizada uma missa em ação de graças, coros, desfiles de nossos estudantes, corpo de bombeiros e nosso glorioso $8^{\circ}$ Regimento de Infantaria, no palanque estavam as principais autoridades de nosso município. ${ }^{24}$

Câmara homenageia Forças Armadas no Aniversário da Revolução de Março / Foi homenageado o $8^{\circ} \mathrm{R}$. I. pela Câmara de Vereadores pelo $1^{\circ}$ aniversário da revolução democrática que desmantelou a articulação comunista, contaram com a presença do Cel. Antonio Joaquim da Silva Neto, que falou da importância da revolução para a manutenção dos setores democráticos brasileiros, em seguida homenagearam o glorioso exército os vereadores Sildo Goetter, pelo PDS, Lucewal Schiedeck pelo PL, Guilherme Dorfey, pelo PRP, Roberto A. Hartungs, pelo PTB; e Jürgen Klemm, pelo PDC. ${ }^{25}$

$2^{\circ}$ Aniversario da Revolução Democrática Brasileira / Escreve Tenente Coronel Irani Siqueira: No próximo dia 31 de março toda a Nação Brasileira estará comemorando o $2^{\circ}$ aniversário do patriótico movimento libertador de 31 de março de 1964. Iniciamos hoje a semana de festi-

24 Gazeta do Sul, ano $21, n^{\circ} 37,1^{\circ}$ de abril de 1965, p.I.

25 Gazeta do Sul, ano $21, n^{\circ} 40,8$ de abril de 1965, p.I. 
vidades relacionadas a tão grande acontecimento, que mudou definitivamente os rumos da Pátria, orientando-a em direção ao futuro promissor, em sua liberdade democrática e cristã. Nesta fase da história da nacionalidade, quando se realiza no país grandiosa obra de restauração nacional, através de uma verdadeira REVOLUÇÃO DEMOCRÁTICA, que se confunde com o próprio destino da pátria, não devemos nos impressionar, nem olhar com pessimismo, por um ou outro aspecto que nos pareça negativo. Se existirem, são tão diminutos que, dada a grandeza do que se realiza, se perdem e se desfazem. Sabemos que só mesmo por obra de um milagre seria possível, da noite para o dia, de um ano para o outro, mudar e renovar completamente um país, antes enfraquecido pelo caos político, econômico e social, sob a égide de um governo irresponsável e infiltrado de comunistas e na triste iminência de desaparecer como nação soberana. Milagre, inspiração, proteção divina, já foi isto, sim, o afastamento definitivo, de nossos horizontes, da ameaça vermelha!

\section{$[\ldots]$}

Expressamos, portanto, agora mais do que nunca, a certeza de que, se cada cidadão, de qualquer credo ou classe social, trabalha com honra, lealdade e dignidade, persistindo no cumprimento do dever para com a pátria que the deu berço; se todos se irmanarem em um ideal comum, em breve chegaremos ao objetivo almejado: o da consolidação da nossa liberdade, e veremos o Brasil firmar-se no conceito das nações e a nossa vontade estará sempre mobilizada no sentido de que nossa família, nossa Pátria, jamais sofram o cativeiro do comunismo.

Tenhamos fé e coragem, Deus está conosco, porque a cruz e a espada uniram-se para salvar nossas instituições. ${ }^{26}$

Quando foi decretado o Ato Institucional no 02, a elite local manifestou seu apoio, deslocando o debate em torno dos acontecimentos políticos para o discurso de valorização do trabalho. $\mathrm{O}$ artigo publicado no jornal ilustra o posicionamento e os valores defendidos por esse segmento:

Bem recebido o Ato $n^{\circ} 02$

Prefeito Orlando Baumhardt: "A hora não é de fazer política, mas de trabalhar pelo Brasil: Povo quer paz e tranquilidade para trabalhar, e não lhe importam as fofocas políticas. Presidente da Câmara Victor Baumhardt: Presidente Castelo Branco procura acertar e está acertando. Extinção dos partidos foi medida muito boa.

Eis o que declarou o prefeito Orlando Baumhardt:

Apoio integralmente o Ato Institucional nº2. A medida é acertada, pois a hora não é de fazer política, mas de trabalhar pelo Brasil. É chegado o momento de, todos unidos, construirmos uma Pátria grande para nós e nossos filhos.

26 Gazeta do Sul, ano 22, $n^{\circ} 36,26$ de março de 1966, p.I. 
E ressalta:

O ato era necessário. Tanto assim, que até era esperado. O povo recebeu a medida com muita simpatia, pois o que todos queremos é paz e tranquilidade para podermos trabalhar e produzir. Ao povo não interessam as fofocas políticas.

Eis o que declarou o presidente da Câmara:

Sou admirador incondicional de nosso presidente Marechal Humberto de Alencar Castelo Branco. E justifico: todas as atitudes por ele tomadas mostram claramente seu único propósito: acertar. E vem fazendo satisfatoriamente, não dando ouvido a certos grupos, na maioria das vezes unicamente interessados em tirar proveito político da situação. Sua meta é unicamente endireitar este país, criando um clima de confiança no governo, o que logicamente encoraja as classes produtoras a novos investimentos, proporcionando maior produção e mais oportunidade de emprego. Em resumo: é um presidente cuja política é única e exclusivamente de criar condições para o progresso, o bem-estar e a felicidade do povo brasileiro.

Se nosso presidente decretou o Al 02, foi porque havia necessidade de fazê-lo. Quanto ao cancelamento do registro de todos os partidos creio que foi uma medida acertada, pois a proliferação de partidos só enfraquece a todos eles. Sou da opinião que devemos reunir os reais valores, em apenas dois partidos. A Nação brasileira certamente muito lucrará com isso. ${ }^{27}$

A maioria dos integrantes da elite local ingressou no partido de sustentação do Regime Militar: a ARENA. Essa postura, no entanto, não ocorreu de maneira homogênea, pois uma parcela de integrantes do antigo PTB iria se filiar ao partido de oposição, o $\mathrm{MDB}$, que seria minoria na primeira década do regime.

\section{Considerações finais}

Esse trabalho procurou caracterizar a formação política do Município de Santa Cruz do Sul entre os anos de 1889 até 1965 tendo como base uma análise bibliográfica em diferentes áreas do conhecimento. Lançamos mão de fontes documentais constituídas por peças jornalísticas produzidas pela imprensa local e documentos institucionais da Câmara de Vereadores ou da Associação Comercial e Industrial além do banco de dados eleitorais da cidade. Buscamos compreender a dinâmica da cultura política local que foi tema analisado por outros pesquisadores que argumentam existir uma fragilidade da prática democrática local.

27 Gazeta do Sul, ano 21, n 127, 30 de outubro de 1965, p.I. 
Há uma tendência histórica de vários grupos sociais da comunidade em aderir ao autoritarismo, à violência e ao conservadorismo. Citamos alguns conflitos que ocorreram ao longo do século XX e que tiveram impacto na vida cotidiana, como a tentativa de assassinato do líder local Carlos Trein Filho, ou mesmo, na década de 1960, o assassinato do deputado estadual Euclides Nicolau Kliemann. Além disso, por se tratar de uma comunidade de imigrantes alemães, em que a relação entre católicos e luteranos sempre foi tensa desde a Reforma Protestante do século XVI e, portanto, importante para a compreensão da política local da colônia até a I República.

Com isso, foi realizado a descrição do panorama eleitoral do desempenho de católicos, representados pelo Partido do Centro Católico, e protestantes, representados pelo Partido Liberal (Federalistas). Constatamos que ocorreu uma gradual perda de força da cisão religiosa na comunidade ao longo da I República, que pode ser visualizado quando comparamos isoladamente cada agremiação partidária com os resultados de cada pleito no contexto de 1889 até 1930 .

Esse processo, segundo análises de Schmidt e Krause, ocorreu por conta da conjuntura histórica de consolidação da separação entre Igreja e Estado, muito forte com a derrocada da Monarquia e a implantação da República. Merece destaque a forte influência do positivismo no Rio Grande do Sul, de tendência anticlerical, representado pelo Partido Republicano Riograndense, hegemônico no estado, procurou, ao longo da I República, cooptar lideranças das duas forças eleitorais de Santa Cruz do Sul. Com o esvaziamento do discurso ideológico assentado na questão religiosa, os líderes do PRR acabaram obtendo sucesso no estabelecimento de uma base eleitoral homogênea e hegemônica na comunidade.

A análise sobre a dinâmica eleitoral no pós-1930 permitiu visualizar os vínculos entre as transformaçóes nacionais e seu impacto na esfera local, como foi possível observar em Schmidt o crescimento gradual do campo "progressista populista" em diferentes eleiçôes. Mas a conjuntura histórica de maior engajamento da defesa do espaço local foi o posicionamento da elite local no Movimento Pela Legalidade. A cidade organizou um comitê de alistamento para uma eventual guerra civil, no entanto, os mesmos in- 
tegrantes que se engajaram nessa mobilização apoiaram o Golpe de 1964. Os eventos políticos analisados nesse texto somente reforçam a tese de outros pesquisadores sobre a tendência de grupos locais em defender seu espaço de atuação estabelecendo vínculos com os segmentos dominantes.

\section{Referências}

CADONÁ, M. A. Expansão e consolidação do capitalismo e formaçáo da classe industrial em Santa Cruz do Sul (1940 a 1976). 2002. 120 f. Relatório de Pesquisa. Departamento de Ciências Humanas, Núcleo de Pesquisa Social, Universidade de Santa Cruz do Sul, Santa Cruz do Sul, 2002.

FERREIRA, J. A Legalidade Traída: os Dias Sombrios de Agosto e Setembro de 1961. Tempo, Rio de Janeiro, v. 2, n. 3, p. 149-182, 1997.

FONSECA, P. D. RS: economia e conflitos políticos na República Velha. Porto Alegre: Mercado Aberto, 1983.

GAZETA DO SUL. Jornal Gazeta do Sul. ano 17, no 103, 29 de agosto de 1961. Editora Santa Cruz Ltda.: Santa Cruz do Sul, 1961. Disponível no Arquivo do Grupo de Comunicaçóes Gazeta do Sul, Fundo Jornais Antigos.

GAZETA DO SUL. Jornal Gazeta do Sul. ano 17, no 105, 02 de setembro de 1961. Editora Santa Cruz Ltda.: Santa Cruz do Sul, 1961. Disponível no Arquivo do Grupo de Comunicaçôes Gazeta do Sul, fundo: jornais antigos.

GAZETA DO SUL. Jornal Gazeta do Sul. ano 21, no 37, 1º de abril de 1965. Editora Santa Cruz Ltda.: Santa Cruz do Sul, 1965. Disponível no Arquivo do Grupo de Comunicaçôes Gazeta do Sul, fundo: jornais antigos.GAZETA DO SUL. Jornal Gazeta do Sul. ano 21, no 40, 8 de abril de 1965. Editora Santa Cruz Ltda.: Santa Cruz do Sul, 1965. Disponível no Arquivo do Grupo de Comunicaçôes Gazeta do Sul, fundo: jornais antigos.

GAZETA DO SUL. Jornal Gazeta do Sul. ano 21, no 127, 30 de outubro de 1965. Editora Santa Cruz Ltda.: Santa Cruz do Sul, 1965. Disponível no Arquivo do Grupo de Comunicaçôes Gazeta do Sul, fundo: jornais antigos.

GAZETA DO SUL. Jornal Gazeta do Sul. ano 22, no 36, 26 de março de 1966. Editora Santa Cruz Ltda.: Santa Cruz do Sul, 1966. Disponível no Arquivo do Grupo de Comunicaçóes Gazeta do Sul, fundo: jornais antigos.

GERTZ, R. O perigo alemáo. Porto Alegre: Ed. da UFRGS, 1991.

KRAUSE, S. Migrantes do tempo: vida econômica, política e religiosa de uma comunidade de imigrantes alemães na República velha. Santa Cruz do Sul: EDUNISC, 2002.

HOBSBAWM, E. Era dos Extremos: o breve século XX. São Paulo: Companhia das Letras, 1996. 
JOB, L. da C. Os colonos do fumo: tobacco pays my bills. Estudo antropológico sobre política, etnia e identidade no Universo da Agricultura Familiar Fumageira em Santa Cruz do Sul Vale do Rio Pardo - RS. Orientador: Daisy Macedo de Barcellos?. 2003. 120 f.. Dissertação (Mestrado em Antropologia Social) - Programa de Pós-Graduação em Antropologia Social, Universidade Federal do Rio Grande do Sul (UFRGS), Porto Alegre, 2003.

LOVE, J. O regionalismo gaúcho. São Paulo: Perspectiva, 1975.

MARTINY, C. “Os seus serviços públicos e políticos estáo de certo modo ligados à prosperidade do município": constituindo redes e consolidando o poder: uma elite política local (São Sebastiāo do Caí, 1875-1900). Orientador: Eliane Cristina Deckmann Fleck?. 2010. 362 f. Dissertação (Mestrado em História) - Programa de Pós-Graduação em História, Universidade do Vale do Rio dos Sinos São Leopoldo, 2010.

MONTALI, L.

NORONHA, A. E. Beneméritos empresários: história social de uma elite de origem imigrante do sul do Brasil (Santa Cruz do Sul, 1905-1966). Orientador: Flávio Madureira Heinz ?. 2012. 370 f. Tese (Doutorado em História) - Programa de Pós-Graduação em História, Pontifícia Universidade Católica do Rio Grande do Sul, Porto Alegre, 2012.

SCHMIDT, J. P. Capital social e participaçáo política em Santa Cruz do Sul: um paradoxo. 2004a. Disponível em: http://online.unisc.br/acadnet. Acesso em: 5 maio 2005.

SCHMIDT, J. P. Comportamento eleitoral e ideologias em Santa Cruz do Sul: o nazismo, o integralismo e a esquerda. 2004b. Disponível em: http://online.unisc.br/acadnet. Acesso em: 10 maio 2005 .

SCHMIDT, J. P. Continuísmo e conservadorismo nas eleiçóes de Santa Cruz do Sul. 2004c. Disponível em: http://online.unisc.br/acadnet/moduloEleicoes. Acesso em: 8 maio 2005.

SKIDMORE, T. E. De Getúlio Vargas a Castelo Branco. Rio de Janeiro: Paz e Terra, 1988.

TELLES, L. da S. Heinz Von Ortemberg: o médico do Kaiser e de Santa Cruz do Sul. Porto Alegre; São Lourenço de Brindes: Escola Superior de Teologia; APESC, 1980.

VOGT, O. A produçáo de fumo em Santa Cruz do Sul - RS (1849-1993). Santa Cruz do Sul: EDUNISC, 1997.

VOGT, O. O Alemanismo e o "perigo alemão" na literatura brasileira da primeira metade do século XX. Signo, Santa Cruz do Sul, v. 32 n 53, p. 225-258, dez, 2007. 


\section{The political formation in a German immigrants community in southern Brazil: the case of Santa Cruz do Sul (from the First Republic to the Military Regime, 1889-1965)}

\section{Abstract}

This paper presents a discussion on the political formation in a German immigrants community in southern Brazil, more precisely in the city of Santa Cruz do Sul, which is located $200 \mathrm{~km}$ away from Porto Alegre, the capital of Rio Grande do Sul. The period analyzed is from 1889, which represents the Republic implementation, to 1965, the year when the second Institutional Act was instituted, within the Military Regime context. Based on a literature review on the local political history, supported by journalistic and institutional sources as well as electoral database of Santa Cruz do Sul, it is intended to describe the local politics dynamic into four parts: the first, analyses the fragility of the local democratic culture and its tendency to authoritarianism and conservatism; the second, approaches the relations between politics and religion in the First Republic; the third, characterizes the electoral continuity and conservatism, which was perpetuated after the Revolution of 1930; the fourth, describes the local elite position towards the legality movement as well as in relation to the military regime implementation.

Keywords: Santa Cruz do Sul. Authoritarianism. Local/regional political history. Military regime. Brazil Republic. 